\begin{tabular}{lllllllllllllllllllllllllllllllll}
\hline$R$ & $E$ & $V$ & I & S & T & A & D & E & E & S & T & U & D & I & O & S & I & N & T & E & R & N & A & C & I & O & N & A & L & E & S
\end{tabular}

\title{
Chile y Bolivia en cuatro obras
}

- Maira, Luis y Javier Murillo de la Rocha

El largo conflicto entre Chile y Bolivia, Santiago, Aguilar Chilena de Ediciones, 2004

- Pérez Yoma, Edmundo

Una misión. Las trampas de la relación chileno-boliviana, Santiago, Random House Mondadori, 2004.

- Pinochet de la Barra, Oscar

Chile y Bolivia. ¡Hasta cuándo!, Santiago, LOM, 2004.

- Bustos, Carlos

Chile y Bolivia: un largo camino. De la Independencia a Monterrey, Santiago, ADICA, RIL Editores, 2004.

En los últimos meses, cuatro obras han visto la luz en nuestro país sobre las relaciones entre Chile y Bolivia. La línea de unión parece encontrarse en el interés que despertó, en un medio informado como en el que se mueven los autores, el devenir de la relación bilateral en el contexto del diálogo sin exclusiones enunciado en Algarve, Portugal, a partir del año 2000.

Paradójicamente, en el ambiente chileno la presentación de este concepto que evoca sutilmente el tratamiento de la cuestión marítima boliviana en un sentido amplio, inclusivo de alcances en cuanto a concesiones soberanas y con connotaciones territoriales, no parece haber despertado el mismo nivel de entusiasmo que en el pasado, como lo mostrarían tendencias de opinión divulgadas en la prensa en el último año ${ }^{1}$.

Luis Maira y Javier Murillo de la Rocha ofrecen dos visiones

$1 \quad$ Radio Cooperativa, 21/01/2004. 
de un mismo tema en El Largo Conflicto entre Chile y Bolivia ${ }^{2}$; Edmundo Pérez Yoma escribe sobre Una Misión. Las Trampas de la Relación Chileno-Boliviana; el diplomático Oscar Pinochet de la Barra llama la atención con un Chile y Bolivia: ;Hasta cuándo!, y Carlos Bustos, también diplomático, ofrece una obra de corte histórico que titula Chile y Bolivia. Un largo camino de la Independencia a Monterrey.

¿Qué tienen estas obras en común? Todas ellas postulan tesis y conjeturas que tienden a dar respuesta a dos preguntas centrales: ¿por qué Chile y Bolivia no tienen relaciones normales en el nivel político (diplomático) como corresponde entre países vecinos? ¿Cuáles son los elementos esenciales que impiden modificar radicalmente esta situación?

A ellas, los autores agregan propuestas de agenda, y que en diferentes sentidos revelan sus propias convicciones. Así, Pinochet de la Barra recuerda el estatuto del territorio antártico para sugerir una extensión analógica a Arica, ejercicio difícil en todo sentido por cuanto la esencia del elemento soberano difiere considerablemente en ambos casos y no se visualiza cómo podría la población de Arica y Parinacota aceptar una disolución de su pertenencia nacional y soberana en un modelo territorial con jurisdicciones múltiples.

La obra de Bustos, con toques personales y en una sucesión de capítulos difíciles de concebir como un continuo que realmente dé cuenta de las relaciones chileno-bolivianas, ya sea sobre el tema del río Silala, las interpretaciones sobre la Asamblea de la OEA en La Paz en 1979, o las negociaciones de los ochenta, entre otras, tiene el mérito de recordar una serie de oportunidades, antes y después de celebrado el Tratado de Paz y Amistad de 1904 entre Chile y Bolivia, en las cuales la cuestión marítima ha estado presente y en algunos casos, llevó a considerar una eventual cesión territorial con compensaciones. Su lectura es altamente recomendable, sobre todo porque aporta evidencias de que no es efectivo que la Cancillería chilena, y quienes se han ocupado de los asuntos bolivianos a lo largo de décadas y distintos gobiernos, y sobre cuya labor es difícil formarse una opinión dada la reserva de su trabajo, hayan sido indiferentes, o mostrado distan-

2 La obra incluye una reflexión de Mónica Hirst. 
cias con la búsqueda de elementos generadores de acuerdos en materia de desarrollo e integración.

Las iniciativas de toda suerte que muestra la historia marcan tendencias que van precisamente en otro sentido. De allí que se ha hablado de gradualistas o no gradualistas en cuanto a las materias atinentes a concesiones soberanas o a la extensión de privilegios a favor de Bolivia.

La tradición diplomática chilena muestra más bien episodios que son recordados o conocidos por la tendencia a poner de relieve la relación con Bolivia, incluso a riesgo de plantear de vez en cuando tesis claramente idealistas, a veces injustamente criticadas, ya que solieron recibir alabanzas inicialmente pero ante su fracaso o el desencanto en los medios políticos, fueron criticos severos de las mismas. Incluso algunos personeros se mostraron más osados, y han llegado a formular observaciones sobre la situación vecinal en un concepto integral, en el sentido de que Chile debe paliar o reparar lo que se visualiza como una indiferencia a su entorno próximo.

La obra de Oscar Pinochet de la Barra, con estilo conciso y un gran manejo del lenguaje, identifica personajes y momentos en que - estando aún vivo y sin resolución el tema Tacna-Arica antes de 1929- personalidades chilenas vieron oportunidades de otorgar concesiones, que entrarían en esas tendencias. Hace pocos años, nuevamente la diplomacia chilena hizo referencia a formas imaginativas, prácticas, realistas, sin cesión soberana hacia Bolivia, como expresión de la misma voluntad.

La frase mal atribuida a la diplomacia chilena en el sentido de que las mejores relaciones con Bolivia son aquellas que existen cuando no se tienen relaciones diplomáticas, y que suele recordarse, no aparece fundamentada en documentos oficiales de la Cancillería; por cierto no lo ha sido en los últimos años. El recuerdo de esta supuesta afirmación, cuyo origen sería más un buen título de prensa que una opinión de expertos, tiende a inducir la idea de que el tema de Bolivia es un asunto mal llevado.

Ante esta multiplicación de obras chilenas, la lectura de Oportunidades Perdidas de Walter Montenegro ${ }^{3}$, es altamente recomendable. Desde ella, se visualiza la perspectiva de la otra parte,

$3 \quad$ La Paz, Los Amigos del Libro, 1987 
que suele faltar en los análisis nacionales. También ayuda "Charaña"4, de Salazar, Gumucio, Orozco y Salazar, obra esta última que sirve para apreciar el sofisticado proceso, llevado a cabo entre 1975 y 1978, imperfecto, pero demostrativo de la voluntad de la época, y la decisiva participación del Perú en el mismo, desde una perspectiva ciertamente boliviana. Diversos trabajos sobre lo que se ha denominado la "política de reintegración marítima" que comprende alternativas bi y multilaterales, explican mejor la compleja definición que significa para Bolivia abordar una relación "normal" con Chile, a partir de otra definición previa que tiende a poner en el centro la obtención de una salida útil y soberana al mar.

La falta de relaciones diplomáticas desde la ruptura con que terminan dichas negociaciones aparece entonces como un mecanismo sancionador hacia la parte chilena, que buscaría privar a nuestro país de un canal normal de interlocución. Al cabo de tantos años, cabe preguntarse, como lo hacen algunos autores bolivianos, si no ha sido Bolivia la que ha resultado limitada en su capacidad de representación ante el gobierno chileno; por el otro lado, para algunos sectores chilenos tales relaciones constituyen un fin en sí mismo, por lo que bien valdrían concesiones y promesas. Hasta ahora, más allá de cortesías, la política boliviana ha mostrado que no se convence con ese enfoque.

La obra de Maira y Murillo es la que más se acerca a entregar elementos explicativos sobre los hechos conocidos en los últimos años, a pesar de que el contrapunto entre sus aportes muestra una enorme distancia tanto conceptual como de enfoque. Mientras Maira plantea un ejercicio acerca de cómo podrían reenfocarse las relaciones, y sugiere -con más realismo que otros autoresque puede seguirse una ruta en varios sentidos simultáneos, partiendo de un fuerte ingrediente de integración, Murillo, aporta elementos para explicar por qué de ese modo tales objetivos no han podido lograrse entre Chile y Bolivia, y sigue una pauta de análisis que no admite concesiones, dado el fracaso de la experiencia del proceso de Charaña (1975-1978).

Curiosamente, la perspectiva que desarrolla Murillo -quien tiene experiencia en los temas de Chile por cuanto participó en

$4 \quad$ La Paz, CERID, 2001. 
forma directa y principal del proceso de Charaña en los años setenta- sobre los últimos años, especialmente durante aquellos en los que él sirvió como ministro de Relaciones Exteriores desde 1997 hasta la enfermedad del presidente Banzer en 2001, es muy distinta de la que expone el relato de Pérez Yoma, sobre el mismo período. Tal vez el trabajo de Javier Murillo, el único boliviano de los autores que comentamos, revela a través de sus interpretaciones más que otros acerca de por qué el tema del río Silala o la cooperación en materia de recursos naturales o los corredores de interconexión -de actualidad en los últimos años- no se ordenan en la misma lógica para Bolivia que para los chilenos y, en consecuencia, sin decirlo sugiere guardar una gran mesura al momento de alentar posibilidades a partir de esos elementos.

Pérez Yoma insinúa a su vez otra hipótesis, en cuanto a que desde el inicio habría existido una diferencia entre el significado político del proyecto específico del gas natural licuificado o LNG, estratégico sin duda para Bolivia, y el tema territorial-marítimo, y que habría constituido una sorpresa que pretendiese vinculárselos. Las fuentes bolivianas -y la abierta invitación a convocar foros facilitadores subregionales y externos para iniciar negociaciones sobre la soberanía y la insinuación desde el inicio de que Perú podría participar en un ejercicio de cooperación política y económica en torno a un polo tripartito de desarrollo- indicarían que ambos temas nunca habrían estado totalmente desligados.

Los signos dominantes de las relaciones que fueron puestos de relieve por las negociaciones sobre el proyecto de salida por la costa chilena del gas natural licuificado (LNG en inglés) proveniente de fuentes bolivianas, son analizados sin titubeos por Murillo, en relación con la posibilidad que ello brindaba para llevar a Chile a la mesa de negociación para lograr una cesión de territorio. Se trataría de alcanzar, a partir de un cambio progresivo en la correlación de fuerzas, que Chile aceptase colaborar en esas negociaciones (con o sin apoyo de terceros facilitadores). Así lo plantean diversos estudios públicos bolivianos de la época, que proponen la configuración de un polo tripartito de desarrollo que se enuncia para involucrar simultáneamente la cooperación entre regiones vecinas de Perú, Chile y Bolivia, de forma de generar un escenario favorable al otorgamiento de mayores concesiones de parte de Chile en Arica, en pro de sus países vecinos. Ello, por cuanto para 
algunos, al abordar la cuestión marítima debe cambiarse el contexto en que se desarrolló el proceso de Charaña, y generar por tanto un ambiente que influya o favorezca el otorgamiento de concesiones territoriales.

En estas obras queda sin respuesta una pregunta. ¿Por qué Chile y Bolivia recorren una y otra vez un camino en el que se cruzan, colaboran un cierto tiempo y no convergen posteriormente? Los autores mencionados esbozan algunas respuestas, diferentes unas de otras; conservadurismo chileno, incapacidad analítica o timidez de su elite diplomática, falta de unidad o madurez boliviana, son propuestas rápidas ante esa pregunta.

Hace falta leer muchas obras de autores bolivianos para captar las sutilezas de sus ideas y por donde esperan encontrar respuestas. El conocimiento de las que puedan entregar los chilenos será también parte de la tarea, en especial sobre el tenor de la relación entre Bolivia y Perú que se proyecta en los temas expuestos, la claridad en el análisis de los elementos políticos dominantes y, particularmente, en el enfoque que se aplique para responder si es posible diseñar caminos, a partir de supuestos que no se sustenten en ideas contradictorias, como que un país es solamente deudor y el otro simplemente una víctima.

María Teresa Infante 